\title{
Editorial: Investigar desde la otredad
}

\section{Gustavo Celedón y Carolina Benavente, U. de Valparaíso}

El número 3 de Panambí. Revista de Investigaciones Artísticas nos permite reflexionar de alguna manera sobre la diversidad de especificidades y singularidades que la exploración artística puede recorrer y crear. Desde la creación manual hasta la reflexión sobre el sonido y la imagen, por ejemplo, hay un sinnúmero de detalles que atraen a sensibilidades dispuestas a abrir todo un mundo alrededor de ellos. Mundos no cerrados que, por lo mismo, permiten darnos cuenta de lo que generalmente no está en nuestro radio de percepción. Sea quizás una de las improntas y responsabilidades de la investigación artística: articular aquello que no tiene medida y lugar en la percepción habitual, planteándole preguntas y problemas que, por un lado, contribuyan a una infatigable y constante rearticulación de sus alcances y, por otro, a la consideración de sensibilidades diferentes e impensadas.

Esto es muy distinto a una multiplicación de los objetos de estudio, a una suerte de extracción desmesurada de objetividades que se transformarían en productos de conocimiento o percepción. Por el contrario, frente a esa tendencia, la investigación en general podría considerar que las dimensiones perceptivas e intelectivas, presentadas siempre bajo el supuesto de su separación, no se resuelven ni en el descubrimiento ni en la invención de una cosa, sino más bien en la actividad constante que se moviliza a partir de la indeterminación que las inquieta. El Ilamado "producto" no finaliza por el sello de su comprensión o el de su percepción. Por el contrario, no finaliza, queda en un cierto grado distante a la investigación, permitiendo que ésta continúe, bajo otra forma, bajo otro título, a cargo de otras subjetividades, de otras personas, de otras disciplinas.

La otredad tiene una presencia destacada en esta versión de Panambí, aunque bajo perfiles diferentes, de los cuales podemos destacar dos. Uno de ellos es el perfil latinoamericanista. La performance duracional "Te regalo una minga", de Nancy Gewölb, y el trabajo "Nos come el paisaje", desarrollado por Isabel Santibáñez en una residencia en Colombia, nos sitúan de lleno en ese horizonte estético y poético. Los artículos siguientes se abocan a la tarea siempre necesaria, en contextos de colonialidad, de explorar los enlaces entre las propuestas artísticas continentales y las metropolitanas. Es lo que hacen Gustavo Chataignier, al abordar las relaciones entre Nouvelle Vague y Cinema Novo; Lucía Rey, al indagar la gravitación del futurismo italiano en el pensamiento de José Carlos Mariátegui; y Saulo Magalhaes y Regina Andrade, al elaborar los nexos posibles entre Augusto 
Boal y Jean-Marie Guyau como modo de entrar a la dupla arte / sociedad por medio del Teatro del Oprimido.

Los textos de Sergio Holas-Véliz sobre Ennio Moltedo y de Bruno Jara sobre Hugo Rivera-Scott interrogan las propuestas contemporáneas de artistas de Valparaíso, evidenciando la complejidad que ellas alcanzan, respectivamente, en poesía y artes visuales. Las problemáticas del tiempo y la memoria, ya presentes en esos escritos, emergen asimismo en la aproximación de Juan Manuel Mancilla a una novela gráfica de Joe Sacco sobre el conflicto de Gaza, mientras que Felipe Larrea interroga la noción de "régimen estético de las artes" en Jacques Rancière, señalando la importancia que en él tiene el procedimiento del montaje como apertura a la heteronomía y la multiplicidad.

El ensayo de Felipe Cussen sobre su trabajo Correcciones tiene la peculiaridad de adentrarse en la zona de misterio que, actualmente, constituye la investigación artística; tarea arriesgada, en cuanto desafía ciertos protocolos instituidos, pero que en Panambi es particularmente bienvenida. Esperamos que se multipliquen este tipo de colaboraciones teórico-artísticas que abordan y a la vez performan la materia central de esta publicación seriada.

El segundo perfil de otredad que caracteriza a esta edición de Panambí es el de un conjunto de mujeres que publican textos más bien marginales a la sección central de "Artículos". Es el caso del escrito de Constanza Navarrete sobre la visualidad monstruosa y barroquizante de la fotógrafa chilena Zaida González y es, asimismo, el caso de la reseña de Stella Salinero sobre el libro de Julia Antivilo Entre lo sagrado y lo profano se tejen rebeldías. Arte feminista nuestroamericano. La otra reseña incluida en este número es de Mariana Rosell, quien nos presenta la película de Iciar Bollaín También la Iluvia, mientras que la tesis de Pamela Antillanca versa sobre música y emotividad en tres películas de Studio Ghibli, de Japón.

Si desde esta contribución final volvemos a las páginas iniciales, el perfil feminista o al menos feminizante se completa con las colaboraciones de Nancy Gewölb e Isabel Santibáñez y, un poco más allá, con el artículo de Lucía Rey y su sugerente perspectiva acerca de las diferencias entre Mariátegui y Marinetti. Sin embargo, ningún círculo se cierra y otros cruces, relieves y perfiles son posibles de avizorar y agenciar en esta edición, como seguramente lo harán otras personas, otras subjetividades, desde otros deseos. 